\title{
La dependencia de la verdad a las pasiones*
}

\author{
Jorge Gregorio Posada Ramírez ${ }^{* *}$ \\ Pedro Felipe Díaz ${ }^{* * *}$ \\ Juan Carlos Aguirre García***
}

Recibido: 2 de mayo de 2013 - Aprobado: 7 de junio de 2013

\begin{abstract}
Resumen
Uno de los retos constantes de las ciencias sociales, y en especial, de la filosofía, son las preguntas sobre qué es lo que el hombre ha creído y sobre lo que debería creer. Si bien, buena parte de las ciencias sociales podría leerse desde este par de preguntas, es en el campo de la filosofía, y en especial, en su relación con el concepto de verdad donde cobra un mayor despliegue. Desde la epistemología se afirma que debemos creer en lo verdadero, y se exponen dos teorías que recogen los lugares comunes de la verdad: correspondentismo y coherentismo. En este trabajo se trata de mostrar que, en la vida social, ni la versión correspondentista ni la coherentista son lo suficientemente vinculantes como para llevar a las personas a creer en lo que deberían creer, de acuerdo con los estándares de la epistemología. Se concluye que en el interés humano de aceptar y aprehender la verdad, para establecer qué se debe creer, es necesario un cultivo de la voluntad. Así, se señala que la verdad, y con ella el creer, involucra tanto a la razón como a la pasión.
\end{abstract}

Palabras clave: Creencia, verdad, proposición, pasiones, voluntad

- Artículo de investigación. Algunas de las ideas de este artículo son fruto del proyecto de investigación: "Ontología de la realidad social, una perspectiva de investigación para las ciencias sociales" (Código M.IN03.02.04.F.02), financiado por la Vicerrectoría de Investigación de la Universidad del Quindío. Los autores de este artículo dan expreso crédito y mención a la Universidad del Quindío y a la Universidad del Cauca por los espacios y tiempos brindados para realizar esta investigación.

** Magíster en Filosofía. Miembro del grupo de investigación Razones y acciones, adscrito a la Vicerrectoría de investigación de la Universidad del Quindío. Sus líneas de trabajo son: la epistemología de las Ciencias sociales, la Teoría de la argumentación, y la Filosofía de la acción. Profesor y director del Programa de Filosofía de la Universidad del Quindío (Colombia).Correo electrónico: gposada@uniquindio.edu.co

*** Magíster en Comunicación Educativa. Miembro del grupo de investigación Comunicación, cultura y desarrollo, adscrito a la Vicerrectoría de investigación de la Universidad del Quindío. Sus líneas de trabajo son: la Comunicación para el desarrollo y la Ciudad y los imaginarios urbanos. Profesor y director del Programa de Comunicación social - periodismo de la Universidad del Quindío (Colombia). Correo electrónico: pfdiaz@uniquindio. edu.co

*** Magíster en Filosofía. Estudiante de Doctorado en Filosofía. Miembro del grupo de investigación Fenomenología y ciencia, adscrito a la Vicerrectoría de investigaciones de la Universidad del Cauca. Sus líneas de trabajo son: Fenomenología y Filosofía de las ciencias. Profesor del Departamento de Filosofía de la Universidad del Cauca (Colombia). Correo electrónico: jcaguirre@unicauca.edu.co. 


\title{
Dependency of Truth on Passions
}

\begin{abstract}
One of the permanent challenges of social sciences -philosophy, specificallyare the questions about the man's beliefs and what he should really believe. Although a significant portion of social sciences could be read based on these two questions, they are more extensively treated in the field of philosophy, especially concerning their relationship with the concept of truth. From the epistemology standpoint, it has been affirmed that we should grow concerning truthfulness and two theories involving common places of the truth are exposed: correspondence theory and coherence theory.

This article is intended to show that, in social life, neither correspondent version nor coherence version are sufficiently binding as to make people believe in what they should really believe according to the epistemology standards. It is concluded that the human interest to accept and apprehend the truth in order to establish what one should believe, involves a need for a cultivation of the will. In this way, it has been affirmed that the truth, in conjunction with the belief, involves both reason and passion.
\end{abstract}

Key words: Belief; truth; proposition; passions; will. 


\section{Introducción}

A pesar de sus tecnicismos, algunas teorías filosóficas son muy promisorias para comprender las prácticas humanas corrientes. Este trabajo se suma a los esfuerzos por dirigir algunos de los territorios conceptuales de la filosofía a los contextos cotidianos. Uno en especial motivó el trabajo que los autores presentan en este artículo: el contexto cotidiano en el que se usa el lenguaje con la intención de comunicar enunciados que se asumen como verdaderos. Así, por ejemplo:

a. Un hombre, después de un largo y vacilante cortejo a una mujer, logra hacerla su esposa. Apegado, sobre todo, a sus deseos de estar con ella y a sus creencias de que solo con ella puede ser feliz, soporta continuamente muchos de sus desaires. Un día la encuentra en su cama, besándose apasionadamente con otro hombre. Él le hace el reclamo, pero ella se defiende insistentemente hasta que le dice: "qué tanto me amas, cuando das más crédito a lo que ven tus ojos que a lo que dicen mis palabras". El hombre termina creyendo que la escena que vio era cualquier cosa, menos el adulterio de su mujer.

b. En la Cumbre de las Américas realizada hace un par de años en Cartagena (Colombia), el alcalde de esta ciudad, tras un suceso en el que unos agentes de seguridad del presidente de los Estados Unidos llevaron prostitutas a donde se hospedaban, afirmó que las mujeres que salieron con los agentes y que recibieron dinero por servicios sexuales no eran prostitutas, sino prepagos o damas de compañía. En una oración, el alcalde dijo: "las prepagos de Cartagena no ejercen la prostitución".

c. Un profesor de Sociología afirma que "no hay verdades absolutas", pues todo depende de los contextos en los que se digan las cosas y de las perspectivas de las personas. Dice que "los que afirman que existen verdades absolutas suelen ser dogmáticos y recalcitrantes". Un estudiante le pregunta si la afirmación que acaba de emitir, esto es: "no hay verdades absolutas", es solo su punto de vista, una perspectiva de él como profesor de Sociología, siendo válido también creer, desde otra perspectiva, que hay verdades absolutas. El profesor contesta airadamente que está en un error, pues la única verdad absoluta es que no hay verdades absolutas. En dos oraciones el profesor afirma: "no hay verdades absolutas y esto es una verdad absoluta".

En estos dos últimos casos, los investigadores pudimos percibir nuestra extrañeza, cierta molestia, de que alguien acepte y afirme públicamente algo que es necesariamente falso. El hecho de que sea el alcalde de una de las ciudades más importantes de Colombia, o un profesor universitario quienes crean y sostengan algo tan abiertamente falso ${ }^{1}$ aumentó nuestra estupefacción. No obstante, lo que seguramente produjo nuestra molestia frente a la afirmación: "las prepago no ejercen la prostitución", o al enunciado: "no hay verdades absolutas y esto es una verdad absoluta", no fue la calidad de su oradores, sino que son

1 En el artículo se asume que los enunciados declarativos, es decir, aquellos que tienen la intención de informar acerca de un estado de cosas del mundo, son susceptibles de valor de verdad; en consecuencia, de un enunciado declarativo podemos afirmar que es cierto o falso, pese a que estas evaluaciones en ciertos contextos proclives al relativismo parecen estar en desuso. 
un par de crudas y evidentes contradicciones. La respuesta filosófica clásica sería que la coherencia, esto es, la propiedad de las proposiciones y creencias de estar conectadas mutua y lógicamente es un indicativo de verdad. La contradicción delata incoherencia, es una prueba de falsedad. A pesar de que muchas veces aceptemos lo falso, cuando se advierte sobre la falsedad de una afirmación hay una propensión de la mente a rechazarla, más cuando es una evidente contradicción.

En el primer caso, la proposición: "la mujer no le ha sido infiel a su marido" es verdadera para el esposo, aunque este haya percibido que ella se besaba apasionadamente con otro hombre. En esta situación, como en las anteriores, puede evocarse nuestra oposición a aceptar la verdad de la proposición, y si bien la indignidad del hombre y la desfachatez de su esposa vigorizan nuestro sentimiento de repudio, puede acentuarse que son la indiferencia hacia el modo de ser de las cosas, la falta de respeto hacia los hechos, lo que más motiva nuestro rechazo.

Pero, pese a que esa es la respuesta clásica y, se supone, bastaría para analizar las situaciones problemáticas, las acciones de los personajes de dichas situaciones aún persisten y, por tanto, también la pregunta: ¿por qué el esposo, el alcalde y el profesor de sociología insisten en decir de lo obviamente falso que es verdadero? Estos tres ejemplos, reales aunque extremos, modelan un comportamiento típico en los contextos argumentativos. Políticos, profesores universitarios, amigos, familiares, humanistas, las personas en general, somos proclives a defender ideas falsas como si fueran verdaderas. A pesar de que los hechos nos muestren con contundencia que nos equivocamos, o que al recibir un contraargumento de lo que decimos se nos revele una flagrante contradicción, nos negamos a declinar sobre lo que afirmamos. Por lo regular, somos tan irracionales al persistir en lo que es falso como el esposo, el alcalde y el profesor de sociología.

Frente esta evidencia y ante la insuficiencia aparente de las respuestas clásicas, los investigadores nos dimos a la tarea de plantear el asunto del siguiente modo: ¿por qué si la mente es propensa a rechazar las afirmaciones refutadas por los hechos o que son contradictorias, hay a la vez en nosotros una tendencia a sostenerlas vigorosamente como verdaderas?

La conjetura que pretendemos defender a lo largo del artículo es la siguiente: en el deseo de los filósofos y estudiosos del hombre de hacer de la verdad uno de los valores rectores que guíen las acciones, las teorías que describen las condiciones de verdad de los enunciados son apenas descripciones acerca de cómo se relaciona nuestra mente con la verdad, dejando de lado las conexiones con nuestras pasiones y voluntad. A la manera de Hume, cuando intenta llevar el reconocimiento de lo bueno y lo malo a las pasiones, intentaremos mostrar que en la aceptación de lo verdadero y lo falso, los criterios asumidos desde el entendimiento, y que son los que se describen tradicionalmente, no son suficientes. La verdad, como lo bueno y lo malo, involucra no solo la razón, sino especialmente la pasión.

Para llevar a buen fin nuestra conjetura, seguimos los siguientes pasos: en primer lugar, revisamos las dos teorías filosóficas más relevantes acerca de la verdad: el corresponden- 
tismo y el coherentismo ${ }^{2}$. Como resultado de esta revisión se expone en este artículo la forma en la que esas teorías recogen el rostro chino, esto es, los rasgos comunes de las proposiciones que llamamos verdaderas. A pesar de que abren un núcleo de problemas teóricos, describen lo que cualquier persona alejada de sutilezas filosóficas llama lo verdadero y lo falso. En íntima relación con lo anterior, se pudo comprender que, no obstante su capacidad explicativa, ambas teorías excluyen la importancia de la sensibilidad en el reconocimiento de la verdad. Finalmente, acorde con nuestra conjetura, se puede concluir que lo que les falta al esposo, al alcalde y al profesor de sociología cuando insisten en defender sus afirmaciones, no es la capacidad de reconocer los hechos o la disposición para conectar coherentemente ideas, sino la sensibilidad hacia la verdad.

\section{Metodología}

El proyecto de investigación adoptó el tipo de investigación pura. Como técnica de investigación se usó el "análisis conceptual". Se inició con la revisión crítica de algunos argumentos presentes en la literatura relevante sobre el tema, especialmente de la polémica correspondentismo y coherentismo en torno a la verdad. Se reconstruyeron tales argumentos a partir de dos ejes: su coherencia y capacidad explicativa, y su intento por radicar el valor de verdad de un enunciado en elementos puramente racionales. Una vez hecha la reconstrucción, se decidieron las estrategias de análisis y las tesis que servirían de categorías primarias para la realización de este trabajo: 1. "Verdad como fruto de discernimiento racional": identificar si, en efecto, el único elemento para determinar el valor de verdad de una proposición es el criterio racional; 2. "Verdad y sensibilidad": identificar propuestas que, en el mismo contexto de discusión, aportaran elementos que permitieran revaluar este clásico planteamiento. Posteriormente, se discutieron críticamente las categorías y se las confrontó con la conjetura que pretendíamos defender: que el creer exige de "vivacidad" psicológica, es decir, que también entran elementos de sensibilidad a la hora de valorar una situación; para ello nos apoyamos en la propuesta del filósofo David Hume. Por último, se buscaron nuevas categorías de análisis que nos permitieron ampliar el horizonte comprensivo y fundamentar mejor la respuesta alternativa que se ofrece a la situación problemática que originó nuestra reflexión; tales categorías nuevas fueron aportadas por el filósofo John Searle.

\section{Resultados}

Este trabajo arrojó dos tipos de resultados: el primer tipo surge de la revisión sistemática de la literatura relevante, lo cual permitió reconstruir las dos teorías más representativas

2 Si bien, en la literatura filosófica sobre el problema de la verdad se encuentra un amplio número de teorías que ofrecen interesantes explicaciones, este trabajo se sitúa en dos nociones que se conectan con dos de las intuiciones más recurrentes cuando se intenta aclarar el concepto de la verdad: correspondencia con los hechos, o teoría correspondentista de la verdad, y coherencia lógica entre proposiciones, o teoría coherentista de la verdad. La verdad en sentido pragmatista, o las teorías hermenéuticas, fenomenológicas o intersubjetivas, en tanto ajenas al marco conceptual adoptado en nuestra investigación, no son abordadas en este texto. Para una aproximación de la amplia gama de teorías de la verdad, confrontar: Nicolás $\mathcal{E}$ Frápolli (1997). 
acerca de la verdad; se presentarán bajo los subtítulos: a. "La teoría correspondentista de la verdad" y b. "La teoría de la verdad por coherencia". El segundo tipo de resultados surgió de la consideración de argumentos que respaldaban la conjetura que se defiende en el artículo; de esta manera, puede afirmarse que este resultado conduce a una explicación alternativa de las situaciones problemáticas que motivaron la investigación y, a nuestro juicio, es la más apropiada a la hora de comprender eventos como los reseñados en la introducción. Este segundo tipo de resultados se presentan bajo el título: c. "Verdad y sensibilidad".

\section{a. La teoría correspondentista de la verdad}

Aristóteles, en el Organon, afirma:

(...) Porque el error y la verdad solo consisten en la combinación y división de las palabras. Los nombres mismos y los verbos se parecen, por tanto, al pensamiento sin combinación ni división, por ejemplo hombre, blanco, cuando no se añade nada a estas palabras. Aquí efectivamente nada es aún verdadero ni falso. He aquí una prueba de ello: un hipocentauro, por ejemplo, significa ciertamente alguna cosa; pero no es aún ni verdadero ni falso, si no se añade que este animal existe o que no existe, sea de una manera absoluta, sea en un tiempo determinado (Aristóteles, 1979, p. 49).

De la cita de Aristóteles podemos colegir dos cosas. Primera, en un mundo sin lenguaje, sin descripciones verbales y articuladas sobre los acontecimientos no hay verdad ni falsedad. En la era de los dinosaurios no existía ni lo verdadero ni lo falso, esto porque no había seres que describieran en oraciones las cualidades de las cosas. La verdad y la falsedad solo se dan en el lenguaje, y específicamente, en uno de sus usos, aquel que sirve para describir los hechos del mundo³. Con esto, Aristóteles recoge quizá la intuición menos controvertible en torno al problema filosófico de la verdad, la que señala que la verdad es una cualidad, una forma de evaluación, del lenguaje descriptivo y no de las cosas. Los objetos y sucesos que están y que ocurren en el mundo no son ni verdaderos ni falsos, solo existen. Lo que es verdadero o falso son las descripciones que a través del lenguaje se hacen de ellos ${ }^{4}$. Por ejemplo, no es correcto decir que: "La Antártida es verdadera o falsa"; lo verdadero o falso es la descripción que se hace de ella, pues este continente como tal no es ni verdadero ni falso.

Lo segundo que puede derivarse de la cita de Aristóteles es que solo en la combinación de las palabras con el objetivo de describir las cualidades de los objetos o sucesos,

3 Esta idea se conserva en la contemporaneidad. Ver, a modo de ilustración, cómo el filósofo del lenguaje John Austin (1991), con su influyente Teoría de las emisiones realizativas, mostró que el lenguaje, siendo en esencia un instrumento, presenta múltiples usos, y uno en especial se da cuando se indaga por la verdad. Austin lo clasificó como el uso constatativo o descriptivo del lenguaje.

4 Filósofos modernos tan disímiles como Descartes (2009, especialmente la Meditación III), Hobbes (1994), o contemporáneos como Wittgenstein (1994) y Heidegger (2006), coinciden en que la verdad es una propiedad exclusiva del lenguaje, no de las cosas o hechos materiales. Lo que puede resumirse en las palabras lapidarias de Hobbes: "Porque la verdad y la falsedad son atributos del lenguaje, no de las cosas. Y donde no hay lenguaje no hay tampoco verdad ni falsedad (Hobbes, 1994, p. 26). 
puede darse la verdad. En una mente atomizada en la que las palabras se dieran discretas, aisladas, sin relaciones entre ellas, careceríamos, igualmente, de la verdad. Mesa, madera, la, es, de, son palabras que, en tanto aisladas, no permiten la verdad ni la falsedad. Decir: "la mesa es de madera", sí permite la valoración de verdadero o falso. Es en el acto de juzgar, esto es, de formar juicios para afirmar o negar que una propiedad o cualidad le pertenece, o no, a un sujeto en donde surge la posibilidad de la verdad.

De este modo, la verdad es una cualidad del lenguaje, una propiedad de las oraciones que usamos para describir los hechos o sucesos del mundo. Los enunciados: "hay una persona leyendo este escrito", "el filósofo que fue maestro de Platón nació en Atenas", "la Selección de Fútbol del Brasil ganó el Mundial de Fútbol realizado en 1950", "en este momento está lloviendo en China", son oraciones que tienen la propiedad de ser verdaderas o falsas. Las dos primeras oraciones: "hay una persona leyendo este escrito" y "el filósofo que fue maestro de Platón nació en Atenas" son verdaderas porque lo que describen corresponde con hechos del mundo. Hay una adecuación entre lo que dicen estas oraciones y el estado de cosas que describen. El enunciado: "La Selección de Fútbol del Brasil ganó el Mundial de Fútbol realizado en 1950" es falso, pues lo que afirma no se corresponde con los hechos del mundo. No hay una adecuación entre lo que afirma y lo que ocurre. Finalmente, el enunciado: "está lloviendo en China", a pesar de que en este momento no podamos decir si es verdadero o falso, tiene un valor de verdad que está determinado por lo que ocurra en el mundo. Si, de hecho, llueve en China en este momento, la oración será verdadera; si no está lloviendo, la oración será falsa. A pesar de que carezcamos de los datos, de las evidencias para saber el valor de verdad de algunas oraciones que describen los hechos, estas necesariamente son verdaderas o falsas.

Lo anterior recoge lo que se conoce en filosofía como la teoría de la verdad por correspondencia, o teoría correspondentista de la verdad. Esta teoría afirma que una proposición es verdadera o falsa en su relación de adecuación o inadecuación con los hechos del mundo. Por tanto, la teoría de la verdad como correspondencia establece que el valor de verdad de los enunciados se da en la relación de las proposiciones con los hechos del mundo.

\section{b. La teoría de la verdad por coherencia}

Pero ¿qué pasa en el caso de oraciones que sabemos que son verdaderas, a pesar de que no las hemos contrastado con los hechos? El enunciado: "la persona que está leyendo este escrito, en este momento, va a morir", sabemos que es verdadero, a pesar de que no ha ocurrido este desafortunado hecho; "mil millones de pesos más dos mil millones de pesos son tres mil millones de pesos", también sabemos que es una proposición verdadera, sin necesidad de ir a confrontar la proposición con los hechos. En el caso del enunciado "las prepago de Cartagena no son prostitutas" sabemos que es falso, a pesar de que no hemos ido a Cartagena a cotejar lo que dice la afirmación con los hechos. El valor de verdad de las proposiciones que no se establece en relación con los hechos se comprende a través de la relación de coherencia de la proposición evaluada con otras proposiciones. A esta forma de presentar la verdad se le llama verdad por coherencia. 
La teoría de la verdad por coherencia afirma que: "una teoría coherentista de la verdad sostiene que la verdad de cualquier proposición (verdadera) consiste en su coherencia con alguna serie especificada de proposiciones" (Young, 2003, p. 111).

Si aceptamos que son verdaderas las proposiciones: "todos los humanos mueren" y "la persona que está leyendo este escrito en este momento es humano", consentimos con la verdad de la proposición: "la persona que está leyendo este escrito en este momento se va a morir"; esto, porque es coherente con las anteriores. En el caso contrario, una proposición que sea incoherente con un conjunto de proposiciones verdaderas, que sea contradictoria con ellas, es necesariamente falsa, en relación con ese conjunto de proposiciones dadas. La teoría de la verdad por coherencia establece que si una proposición (p) es contradictoria con un conjunto coherente de proposiciones, se siguen dos cosas: o el conjunto coherente de proposiciones es falso, y en este caso la proposición (p) será verdadera, o el conjunto coherente de proposiciones es verdadero y (p) es falso. Para el coherentismo la coherencia entre proposiciones determina el valor de verdad, siendo la contradicción el criterio para establecer la falsedad.

\section{c. Verdad y sensibilidad}

$\mathrm{Si}$, de acuerdo con la teoría correspondentista, para creer en el valor de verdad de las proposiciones bastara con la comparación entre las proposiciones y los hechos, ¿̇por qué el esposo, aunque percibe el hecho y dispone de la proposición adecuada, no concluye lo verdadero? O, si el descubrir la contradicción de un enunciado nos advierte acerca de su falsedad, ¿por qué el alcalde o el profesor de sociología no descubren la falsedad de lo que afirman? En una pregunta, ¿por qué las personas no creen siempre en lo que se les presenta como verdadero?

Íntimamente relacionadas, las explicaciones sobre la forma como se asigna el valor de verdad a las proposiciones conducen a la cuestión sobre la forma como se da el valor de verdad de las creencias, y con ello, por qué cree la gente lo que cree. Si se acepta como verdadero el enunciado: "La república de Colombia ha tenido seis presidentes antioqueños" es obvio que se acepte, y con ello se crea que: La república de Colombia ha tenido seis presidentes antioqueños. Así, creer en algo es aceptar que un enunciado o juicio es verdadero; por su parte, consentir con la verdad de un juicio lleva a tener creencia sobre él. Es casi una contradicción lógica decir: "es verdad que el domingo 4 de agosto de 2013 hizo una mañana soleada, pero, yo no creo que el domingo 4 de agosto de 2013 hizo una mañana soleada"; esto porque creencia y verdad son conceptos íntimamente relacionados, aunque no equivalentes.

No obstante, y como se intentará mostrar, el creer comporta un elemento psicológico no necesariamente presente en los enunciados o proposiciones. El creer implica cierta predisposición del ánimo que no necesariamente se restringe a la relación hecho-proposición, como en el caso de la teoría correspondentista de la verdad; contiene cierto elemento conativo, no presente en la exclusiva relación de coherencia lógica entre enunciados, relación que se asume en la teoría coherentista de la verdad. 
Así, esta sección busca presentar, desde las propuestas del filósofo empirista David Hume y del filósofo de la mente John Searle, una teoría de la creencia afín con las intuiciones que corrientemente aceptamos sobre lo que es creer, y tendente a explicar lo que puede estar en juego cuando, a pesar de lo contundente de las evidencias a favor de la verdad de una proposición, las personas no creen en ella. Desde estos dos filósofos, se intentará mostrar que el elemento que marca la diferencia entre tener una proposición verdadera y creer en ella evoca un aspecto emotivo y psicológico, elemento que relaciona el creer en la verdad de una proposición más con lo volitivo y pasional, que con lo lógico y racional.

Consideramos que, si bien elaborar una teoría sobre el creer es un proyecto apenas seminal en las ciencias sociales y humanas, las ideas de los dos pensadores que se despliegan en este escrito pueden ser promisorias en el propósito de comprender las disposiciones psicológicas que inclinan a las personas a creer, y a su vez, a evadir la verdad de afirmaciones que parecen incontrovertiblemente verdaderas, a la luz de las evidencias y la coherencia lógica.

\section{d. David Hume y la vivacidad psicológica del creer}

David Hume, inspirado por los trabajos de Isaac Newton, buscó entender los resortes que mueven la vida mental de los hombres. Según Hume, así como Newton describió las leyes que gobiernan el comportamiento de los cuerpos celestes y terrestres, la ciencia de la moral, o ciencia del pensamiento del hombre, debe explicar los mecanismos mediante los cuales se ordena la vida mental de los hombres. Su obra Tratado de la naturaleza humana (1974) es un riguroso, amplio y consistente estudio sobre el conocimiento, la moral y las pasiones humanas. Fiel a los principios empiristas, garantizó que sus ideas no tomaran la forma gaseosa e impráctica de la metafísica. Así, enmarcado en la actitud empirista elaboró sus consideraciones sobre el creer, uno de los elementos constantes del pensamiento. En el Tratado de la naturaleza humana, escribe:

Esa operación del espíritu que constituye la creencia en un hecho parece haber sido hasta ahora uno de los más grandes misterios en filosofía, aunque nadie haya siquiera sospechado de que hubiese ninguna dificultad en explicarlo. Por mi parte, debo confesar que encuentro una dificultad considerable en el caso y que, aun cuando creo que entiendo perfectamente el tema, no encuentro los términos para expresar lo que quiero decir (Hume, 1974, p. 166).

Desde sus primeras evocaciones al concepto de creencia, Hume manifiesta sus reservas de poder comprenderlo satisfactoriamente en una teoría. Si bien el creer es una actividad constante de la vida mental de las personas, su familiaridad y cercanía hace que sea difícil la distancia necesaria para ser aprendido desde una teoría. Así, para Hume es más fácil mostrar qué es el creer que definirlo; es a través de ejemplos, de casos concretos de creencias, como puede iniciarse algún tipo de explicación sobre este importante aspecto de la vida mental humana.

Hume invita a que utilicemos a la imaginación; así pues, si concebimos la cabeza de un toro unida al cuerpo de un hombre, reconocemos que no tenemos una creencia acerca de 
la existencia real de tal ser. Las personas no creen en la existencia real de los minotauros. "Los minotauros existen como seres biológicos en el mundo" es una proposición que al no aceptarse como verdadera, señala un caso de no creencia. Pero, si imaginamos a un hombre calvo, bajo y gordo, sabemos que podemos tener creencia sobre la existencia de personas con estas características. "Hay hombres calvos, bajos y gordos, como Danny DeVito" es un enunciado que las personas aceptan como verdadero, y que revela un caso positivo de creencia.

Hume dirá que lo que hay en la representación del hombre calvo, bajo y gordo, y que no está en la imagen mental del minotauro, es la cualidad que define el creer. Mientras que en el minotauro se carece de una inclinación de la mente a aceptar que es real, que existe, en el caso del hombre calvo, bajo y gordo, como Danny DeVito, se da una inclinación a asumir su existencia. Hume llama a esta cualidad vivacidad. En las dos imágenes evocadas por las proposiciones: "Los minotauros existen como seres biológicos en el mundo" y del enunciado "Hay hombres calvos, bajos y gordos, como Danny DeVito" existe una operación de la imaginación consistente en recrear mentalmente los sujetos enunciados con sus cualidades. La imaginación configura las dos representaciones abstrayendo y mezclando ideas; sin embargo, no es en las imágenes mismas elaboradas por la imaginación en las que se encuentra ese plus adicional que inclina la mente al creer. Las ideas o imágenes que nos hacemos de las cosas no son suficientes para creer en ellas. En palabras de Hume, el recurso para distinguir las ideas que creemos de las que no radica "(...) en la manera de concebirlas y en el modo como las siente el espíritu" (Hume, 1974, p. 167). Vale la pena resaltar la expresión de Hume: "El modo como las siente el espíritu", pues con ella se empieza a trazar la línea expositiva de su teoría del creer. Para comprender lo que son las creencias hay que evocar el sentir.

Por tanto, para Hume, las ideas que se creen son aquellas que están acompañadas de una la vivacidad o fuerza psicológica, vivacidad y fuerza psicológica que no están presentes en las imágenes que pensamos sin creer. Tomando la invitación de Hume de estar trayendo ejemplos corrientes para entender lo que es el creer, pensemos en la diferencia entre un hombre que representa en su imaginación un objeto volador no identificado, sin creer que se trate de una nave extraterrestre, y el que cree que es una nave extraterrestre, para recrear la noción: "el modo como las siente el espíritu". Ante la proposición: "las naves extraterrestres vuelan por la atmósfera terrestre", el que cree en las naves extraterrestres está en una relación psicológica muy distinta del que no cree en ella. Para Hume, es el tipo de fuerza psicológica o vivacidad en que se da en una y otra persona lo que define el creer. Mientras que en el que no cree concibe la imagen, sin forjar una impresión vivaz, en el segundo, se da la misma imagen, imagen que está coloreada por una fuerte vivacidad psicológica: el creer. Así, el rasgo mental que decide cuáles ideas se creen y cuáles no es la vivacidad psicológica, la disposición sensible de la mente ante ciertas ideas o representaciones.

La diferencia que hay entre las imágenes y proposiciones corrientemente asociadas a hadas, sirenas, vampiros, unicornios y duendes, con respecto a mujeres, peces, murciélagos, caballos y hombres enanos, es que el primer grupo lo concebimos fácilmente en la 
imaginación mezclando ideas, sin que esas imágenes estén permeadas por la vivacidad psicológica del creer; mientras que cada una de las imágenes del segundo grupo está acompañada de una fuerza de impresión que nos hace creer en su existencia.

En síntesis, para Hume, las creencias son representaciones o imágenes mentales acompañadas de una fuerte vivacidad psicológica. Por consiguiente, creemos o aceptamos como verdaderas las imágenes o representaciones que sentimos vivazmente en nuestra mente; las que pasan por ella de apática o indiferentemente no llevan al creer.

Si bien Hume solo da indicaciones para una teoría del creer, su propuesta descubre un rasgo promisorio para su comprensión: vivacidad, o fuerza psicológica de sentir ciertas ideas o nociones. Él mismo lo sintetiza de la siguiente manera: "una idea a la que se asiente, se siente de otro modo que una idea ficticia que solo la fantasía nos presenta, y trato de explicar este sentimiento diferente llamándolo fuerza o vivacidad, o solidez, firmeza, o constancia superiores" (Hume, 1992, p. 167).

Creer implica, entonces, un sentimiento, una disposición psicológica de la sensibi lidad. No basta el ajuste entre la proposición y los hechos, o la coherencia lógica entre proposiciones para tener creencia. Es necesaria esa condición adicional a la mera verdad de las proposiciones, elemento que Hume localiza en la sensibilidad y lo llama vivacidad.

\section{El creer en la filosofía de Searle}

En la literatura reciente, el libro Intencionalidad, un ensayo en la filosofía de la mente (1992), del filósofo de la mente John Searle, expone algunos elementos importantes para seguir avanzando en la consolidación de una teoría sobre el creer. La propuesta de este filósofo de la mente revela una conexión fuerte entre el creer y el valor de verdad de las proposiciones. El propósito inicial de la filosofía de Searle es aclarar cómo es posible que el pensamiento, siendo no físico ni material, represente y se relacione con el mundo, que sí es físico y material. Este asunto recoge un enigma perenne de la filosofía acerca de cómo reconciliar lo mental con lo físico. Para Searle, la pieza clave de este problema filosófico es el concepto de Intencionalidad 5 . Este concepto, sumado a su teoría de los actos de habla, en la que muestra cómo el lenguaje se relaciona con el mundo, permite derivar algunas consideraciones importantes sobre la creencia, pues, la creencia es, justamente, una porción de pensamiento que representa y abstrae rasgos de un mundo físico y material.

Para Searle (1992), las creencias, los deseos, los temores, entre muchos otros, son estados mentales Intencionales, pues se dirigen o representan sucesos del mundo. Así, Intencionalidad es la propiedad de ciertos estados de representar o dirigirse hacia otros estados o sucesos del mundo. Creer que: "el 31 de octubre del 2020 va a llover" o desear que: "la Selección Colombia de fútbol gane el próximo mundial", son estados mentales Intencionales, en tanto ambos representan hechos o posibles sucesos del mundo. El

5 Se escribe Intencionalidad con I mayúscula para marcar que no se trata del estado mental específico de tener la intención de algo, sino de la propiedad de muchos estados mentales de dirigirse o representar sucesos del mundo. 
primero, el hecho de que llueve en la fecha descrita. El segundo, el posible suceso de un grupo de hombres logrando un importante triunfo deportivo.

Para Searle, la Intencionalidad no solo es mental; es decir, representar partes del mundo no es exclusividad de tipos de pensamientos como las creencias y los deseos; existen objetos físicos que también tiene la capacidad de representar. Por ejemplo, el mapa de Cartagena es Intencional, pues representa y se dirige hacia ese hecho que es distinto del mapa mismo: la ciudad de Cartagena. En tanto Intencionales, los estados mentales tienen la misma propiedad de los mapas: representan y se dirigen a sucesos o hechos que son distintos de los estados mentales mismos. Creer que: "la Batalla de Boyacá se llevó a cabo cerca de la ciudad de Tunja" es un estado mental que si bien se dirige y representa un hecho histórico, es distinto del suceso físico que se desarrolló el 7 de agosto de 1819. Las creencias son Intencionales, en el sentido en el que se dirigen y representan estados de cosas distintos del creer mismo.

Lo que determina el carácter de Intencionalidad de las creencias es que no hay creencias simples, todas son complejas. Todo creer es creer en algo. Se cree que "las prepago de Cartagena no ejercen la prostitución", o se cree que "no hay verdades absolutas", o se cree que "esta tarde va a llover"; pero no hay creencia a secas, no se cree y ya, siempre que se cree, se cree en algo. Para Searle ese algo es una proposición. Heredero de la tradición de la filosofía analítica, las creencias más que ser sobre ideas o imágenes, a la manera de Hume, son sobre proposiciones: creer es siempre creer sobre p, y p es cualquier proposición; las proposiciones pueden entenderse como el contenido de creencia. Por ende, las creencias son estados mentales con contenido proposicional.

No obstante, si bien en este momento la teoría de Searle avanza en la caracterización de las creencias, las hace indistinguibles de los deseos, pues los deseos, al igual que las creencias, son siempre sobre p, y con ello, son estados mentales con contenido proposicional. Pero, intuitivamente sabemos que una cosa es creer y otra distinta desear. En la comparación entre creencias y deseos, Searle dará un paso más en la comprensión de lo que son las creencias.

Se dijo arriba que los deseos, al ser estados mentales Intencionales, tienen también contenido proposicional, lo que hasta el momento los hace indistinguibles de las creencias. Cuando se desea, el deseo, en cuanto a episodio mental, se refiere a una proposición. Deseo que "no llueva el domingo", deseo "Viajar a México en las próximas vacaciones", deseo que "para el próximo año el salario mínimo tenga un aumento superior al 7 \%". Al igual que las creencias, los deseos son sobre p, acerca de cualquier proposición.

Para Searle, lo que distingue las creencias de los deseos es lo que él llama modo psicológico. Tomando como modelo su teoría de los actos de habla, en los que, por citar un ejemplo, la fuerza ilocucionaria marca la diferencia entre una orden y un ruego, el modo psicológico determina cuándo se cree, se desea o se teme. Así, dada una misma proposición podemos tener o una orden o un ruego o una descripción, esto debido a su fuerza ilocucionaria. Puede ordenarse que 'Juan viaje a Cartagena', en este caso tenemos una orden; o puede implorarse que 'Juan viaje a Cartagena' en este caso, de la misma 
proposición, tenemos un ruego; o simplemente afirmarse que 'Juan viaje a Cartagena' y tener una descripción. Una misma proposición con distinta fuerza ilocucionaria genera distintos actos de habla.

En los estados mentales Intencionales, el modo psicológico que sobre la proposición se dé determina si se cree, se desea o se teme en ella. La proposición 'el libro está sobre la mesa' puede generar una creencia, un deseo o un temor, dependiente del modo psicológico. En este sentido, se puede creer que 'el libro esté sobre la mesa', desear que 'el libro esté sobre la mesa', o temer que 'el libro esté sobre la mesa'. Al cambiar el modo psicológico de las proposiciones se varía su calidad de estado mental.

Searle propone la fórmula E ( $r$ ) para sintetizar la manera como el modo psicológico, acompañado de una proposición, constituye el estado mental. E representa el modo psicológico, y r el contenido representativo o proposición (Searle, 1992, p. 21). Como señala en Intencionalidad, su teoría es descriptiva. Busca establecer los elementos que, conjugados, constituyen los estados mentales Intencionales, esto es, los episodios mentales que representan y se dirigen a sucesos del mundo, o sucesos que son distintos de los estados mentales mismos. El modo psicológico y la proposición son las dos primeras piezas de su propuesta. No obstante, su investigación no se dedica a indagar por la causa de que se tenga o no un modo psicológico. Searle no explica por qué creemos lo que creemos, o por qué deseamos ciertas proposiciones y no otras. Su teoría es analítica, esto es, describe los componentes de los estados mentales como el creer o el desear, y no su origen.

En este sentido, es interesante volver al filósofo moderno David Hume, pues si bien vivacidad y modo psicológico no son stricto sensu términos extensibles, comparten el rasgo de referirse al tipo de vivencia psicológica que aflora cuando se cree, o se tiene un estado mental como el creer. De Hume y Searle puede colegirse que el contenido de la creencia, llámese idea en el caso de Hume, o proposición en el caso de Searle, obedece al componente intelectual o lógico del creer. En contraste, la vivacidad o el modo psicológico recoge la afección o experiencia sensible interna, que en tanto no es intelectual o proposicional, acoge otro tipo de disposición humana distinta del intelecto o la razón, y que es constitutiva del creer. Hume apela a la sensibilidad o componente pasional humano para explicar el origen del tipo de afección que se da en una idea o representación que se cree, distinguiendo así al entendimiento y nuestras capacidades racionales, de la sensibilidad y las pasiones. A este respecto sostiene:

Ahora bien, es evidente que nuestras pasiones, voliciones y acciones son incapaces de tal acuerdo o desacuerdo, en cuanto son hechos y realidades originales completos en sí mismos, sin implicar referencia alguna a otras pasiones, voliciones o acciones. Es imposible, por consiguiente, que puedan ser considerados verdaderos o falsos, contrarios o conformes a la razón (Hume, 1984, p. 675).

Para Hume, en tanto comparación de las ideas con los hechos, o acuerdo o desacuerdo entre lo que se piensa y lo que es el caso, es la facultad de la razón la que permite esta operación. No obstante, cuando se cree propiamente, cuando se pasa de la proposición y su valor de verdad al estado mental de la creencia, episodio mental en el que se acepta 
y cree en la proposición, el plus adicional puede rastrearse en la sensibilidad. Puede decirse que la vivacidad de Hume y el modo psicológico de Searle, como experiencias internas o maneras de darse una proposición, no son operaciones propias del intelecto sino de la sensibilidad.

Puede concluirse esta parte del texto señalando que, desde la filosofía moderna con Hume y la filosofía contemporánea con Searle, el estado mental del creer, en tanto episodio de la mente, está constituido por dos elementos: (i) la idea o proposición que se cree, a lo que nos hemos referido como el contenido de creencia, y (ii) por la vivacidad psicológica o modo psicológico, al que nos hemos referido como la afección interna que nos inclina a aceptar o no aceptar una proposición. El primer elemento, el contenido de creencia, debido a que se constituye por ideas o proposiciones, pertenece al dominio del intelecto o la razón. El segundo, la vivacidad psicológica, al terreno de las pasiones. Así, para creer en el valor de verdad de una proposición es necesario conjugar tanto las capacidades intelectivas o racionales como las disposiciones propias de la sensibilidad y las pasiones humanas. La percepción de nubes grises, el olor a humedad y la sensación de frío, no son suficientes para creer que va a llover. Es necesaria, además, la inclinación de la voluntad, generada por la vivacidad psicológica, para aceptar el valor de verdad de la proposición y creer en ella.

\section{Conclusiones}

Retomando los casos del hombre que percibe la infidelidad de su mujer, del alcalde de Cartagena y del profesor de sociología, podemos afirmar que si bien disponen de los elementos epistemológicos para aceptar o no aceptar la verdad de las afirmaciones: "las prepagos de Cartagena no ejercen la prostitución", "no hay verdades absolutas y esto es una verdad absoluta", y "mi esposa me es fiel", su negativa a creer lo que deberían creer es un asunto de la voluntad, de lo emotivo o pasional, y no de lo racional. En los dos primeros casos, para reconocer lo verdadero o lo falso se cuenta con la coherencia y su rasgo de evaluación: la contradicción. En el tercer caso, con la evidencia empírica necesaria para decidir justificativamente sobre la verdad o falsedad de la proposición.

Sin embargo, en los tres casos las personas se adhieren a lo que es contrario a la razón, a lo evidente y coherente. Esta escandalosa forma de autoengaño no revela un error en la apreciación de la evidencia, o una insuficiencia en los datos disponibles. Lo que estos casos señalan es nuestra necesaria dependencia a las inclinaciones de nuestras pasiones para aceptar y entender la verdad de las proposiciones. No basta con las evidencias empíricas o la coherencia de las proposiciones para creer en ellas; es condición necesaria una vocación de la voluntad para dejarse llevar por las evidencias y la coherencia, inclinación que no se da en el terreno de lo racional, sino en el de la sensibilidad.

Puede decirse que el esposo, el alcalde y el profesor universitario carecen de lo que tentativamente llamamos una sensibilidad por lo verdadero, privación que les hace impertérritos a reconocer la vivacidad psicológica intrínseca tanto a la evidencia empírica como la coherencia de las proposiciones, con lo que las pasiones, lo emotivo, permean 
significativamente la capacidad de las personas de reconocer y aceptar la evidencia y la coherencia de las afirmaciones. Sostener una proposición como verdadera a pesar de que es incuestionablemente contradictoria o palmariamente negada por las evidencias, no necesariamente señala fallas en las disposiciones racionales o epistemológicas de las personas, sino sobre todo una debilidad de la voluntad ante el deber de inclinarse hacia lo verdadero.

\section{Referencias bibliográficas}

Aristóteles. (1979). Organon. México: Porrúa.

Austin, J. (1991). Emisiones realizativas. En: Valdés Villanueva, L. La búsqueda del significado. Madrid: Tecnos.

Descartes, R. (2009). Meditaciones metafísicas. Bogotá: Universidad Nacional de Colombia.

Heidegger, M. (2006). Carta sobre el humanismo. Madrid: Alianza.

Hobbes, Th. (1994). Leviatán. México: Fondo de Cultura Económica.

Hume, D. (1974). Tratado de la naturaleza humana. Buenos Aires: Paidós. (2010). Investigación sobre el entendimiento humano. Buenos Aires: Losada.

Frápolli, M. E Nicolás, J. (1997). Teorías de la verdad en el siglo XX. Madrid: Tecnos.

Posada, G. (2007). La noción tripartita del conocimiento, una introducción a la epistemología. Manizales: Universidad de Caldas.

Searle. J. (1992). Intencionalidad, un ensayo en la filosofía de la mente. Madrid: Tecnos.

Wittgenstein, L. (1994). Tractatus lógico philosophicus. Barcelona: Altaya.

Young, J. (2003). La teoría de la verdad como coherencia. Discusiones filosóficas, 4, pp. 110-120. 
